\title{
Effect of annealing temperature on microstructure, mechanical and tribological properties of nano-SiC reinforced $\mathrm{Ni}-\mathrm{P}$ coatings
}

Qianzhi Wang ${ }^{\mathrm{a} *}$, Mauro Callisti ${ }^{\mathrm{a}}$, Jake Greer ${ }^{\mathrm{a}}$, Brian McKay ${ }^{\mathrm{b}}$, Tatjana Kosanovic Milickovic ${ }^{\mathrm{c}}$, Alexandros ZoikisKarathanasis ${ }^{\mathrm{c}}$, Ioanna Deligkiozi ${ }^{\mathrm{d}}$, Tomas Polcar ${ }^{\mathrm{a}}$

${ }^{a}$ National Centre for Advanced Tribology at Southampton, Department of Mechanical Engineering, Faculty of Engineering and the Environment, University of Southampton, Southampton SO17 1BJ, UK

${ }^{\mathrm{b}}$ Institute of Materials and Manufacturing, Brunel University, London UB8 3PH, UK

${ }^{c}$ Centre for Research and Technology Hellas (CERTH/IRETETH), Trikala GR42100, Greece

${ }^{\mathrm{d}}$ Centre for Technology Research and Innovation, Limassol 3106, Cyprus

\begin{abstract}
The tribological properties of $\mathrm{Ni}-\mathrm{P} / \mathrm{SiC}$ nanocomposite coatings annealed at different
\end{abstract} temperatures $\left(350-500{ }^{\circ} \mathrm{C}\right)$ were investigated in order to determine the optimal temperature needed to enhance their wear resistance as well as to reveal the underlying wear mechanisms. With increasing annealing temperature, the hardness of the annealed coatings gradually decreased from $8.2 \pm 0.5$ to 7.1 $\pm 0.6 \mathrm{GPa}$ as a result of the Hall-Petch effect, nevertheless these values obtained were constantly higher than that of the as-plated coating $(6.3 \pm 0.3 \mathrm{GPa})$ due to the formation of a hard $\mathrm{Ni}_{3} \mathrm{P}$ phase. Regarding to tribological properties, the $\mathrm{Ni}-\mathrm{P} / \mathrm{SiC}$ coating annealed at $350{ }^{\circ} \mathrm{C}$ presented a poorer wear resistance $\left(6.1 \times 10^{-5} \mathrm{~mm}^{3} / \mathrm{Nm}\right)$ compared to the as-plated coating $\left(3.9 \times 10^{-5} \mathrm{~mm}^{3} / \mathrm{Nm}\right)$ owing to a rougher original contact surface and the subsequent generation of nickel and iron oxides on the wear track. In contrast, coatings annealed at temperatures ranging between $400-500{ }^{\circ} \mathrm{C}$ exhibited the improved wear resistance $\left(4.3 \times 10^{-5}-7.8 \times 10^{-6} \mathrm{~mm}^{3} / \mathrm{Nm}\right)$ attributable to their smoother surfaces and to the lubrication effect of $\mathrm{H}_{3} \mathrm{PO}_{4}$ arising from the tribochemical reaction between $\mathrm{Ni}_{3} \mathrm{P}$ and the environment. Overall, the $\mathrm{Ni}-\mathrm{P} / \mathrm{SiC}$ coating annealed at $500{ }^{\circ} \mathrm{C}$ containing the largest amount of $\mathrm{Ni}_{3} \mathrm{P}$ exhibited the lowest friction coefficient $(0.51)$ and wear rate $\left(7.8 \times 10^{-6} \mathrm{~mm}^{3} / \mathrm{Nm}\right)$.

Keywords: Nickel-phosphorus; SiC; Electroplating; Tribology; Annealing.

\section{Introduction}

Protective coatings have attracted scientific interest for decades due to their potential to increase resistance to wear and corrosion, which are estimated to account for 3-4\% of the world's Gross Domestic Product (GDP) [1]. At present, one of the mostly used coatings in the world is hard chrome,

\footnotetext{
${ }^{*}$ Corresponding author. Tel.: +44-23-8059-4438.

E-mail address: qz.wang@soton.ac.uk; jxwqz1985@aliyun.com.
} 
as it exhibits a unique property that simultaneously helps prevent wear and corrosion. However, $\mathrm{Cr}^{6+}$ (hexavalent chromium) used in electrolytic baths is extremely harmful to both human health and the environment [2]. As a result, hard chrome electroplating must be accompanied by expensive ventilation and complicated waste management systems in order to meet strict legislations [3]. Consequently, Ni-P coatings employing the same deposition technique were introduced, and the influence of the baths parameter [4], surfactant [5], $\mathrm{pH}$ value [6] and post-treatments such as hydrogen plasma [7] and annealing [8] on their comprehensive properties were investigated. Optimised Ni-P coatings are well suited for general applications, especially in corrosive environments, but their hardness and wear resistance are still inadequate for more demanding situations. Hence, various reinforcing particles such as $\mathrm{SiC}[9,10]$, $\mathrm{TiN}$ [11], $\mathrm{TiO}_{2}$ [12], $\mathrm{SiO}_{2}$ [13], WC [14], $\mathrm{Al}_{2} \mathrm{O}_{3}$ [15], $\mathrm{B}_{4} \mathrm{C}$ [16] and CNTs [17] were incorporated into Ni-P coatings to enhance their mechanical and tribological properties. As reported in Table 1, incorporation of reinforcing particles increases the hardness of NiP coatings, especially when SiC particles were used. Moreover, studies [18, 19] have demonstrated that the incorporation of $\mathrm{SiC}$ particles in a Ni-P matrix is the most effective combination of cost and performance in industrial applications.

Regarding Ni-P/SiC composite coatings, SiC particles with a size ranging between $0.5-6.0 \mu \mathrm{m}$ was mostly used [20-25], while only a few studies investigated the use of nano-sized SiC particles $(40-50 \mathrm{~nm})$ [26-32]. However, it is worth noting that these studies investigated only the effects of SiC nanoparticles on the microstructures, corrosion resistance [26-30] and wear resistance of the as-plated coatings $[31,32]$. Therefore, there is still a large gap in the relationship between microstructure, mechanical and tribological properties of Ni-P/(nano)SiC coatings. In particular, the effects of postdeposition heat treatments on the tribological properties is still unexplored.

In this study, $\mathrm{SiC}$ particles with a nanometric size were incorporated in Ni-P coatings, and the effects of different annealing temperatures on the microstructure, mechanical and tribological properties of the composite coatings was investigated and correlated.

\section{Experiment details}




\subsection{Coatings electroplating}

Plasma CVD $\beta$-SiC particles (density of $3.22 \mathrm{~g} / \mathrm{cm}^{3}$, Nanostructured \& Amorphous Materials, Inc.) with a size ranging between $45-55 \mathrm{~nm}$ were used as reinforcement for Ni-P coatings. Carbon steel plate substrates, with a size of $4 \times 6 \mathrm{~cm}^{2}$ and a thickness of $1 \mathrm{~mm}$ were cleaned in solvent, alkaline and acid washes. Before depositions, the substrates were covered with galvanic tape (3M 470 Electroplating and Anodizing Vinyl Tape) so as to leave a $4 \times 4 \mathrm{~cm}^{2}$ exposure area. Direct current (DC) electroplating was performed under a constant current density of $20 \mathrm{~A} \cdot \mathrm{dm}^{-2}$, with the carbon steel plates acting as cathodes and the Ni-S balls in titanium mesh baskets as anodes. In order to ensure a uniform electrolyte solution, a magnetic stirring at $300 \mathrm{rpm}$ was applied. Ni-P/SiC composite coatings (5.9 wt $\%$ P) $\sim 60 \mu \mathrm{m}$ thick were electroplated from a bath containing nickel sulphate as the nickel source, phosphorous acid as $\mathrm{P}$ source, nickel chloride to support the dissolution of Ni-S anode, as well as wetting, buffering and dispersing agents. The deposition parameters for the fabrication of Ni$\mathrm{P} / \mathrm{SiC}$ composite coatings are listed in Table 2.

The as-plated $\mathrm{Ni}-\mathrm{P} / \mathrm{SiC}$ coatings $\left(50{ }^{\circ} \mathrm{C}\right)$ were subsequently annealed at $350,400,450$ and $500{ }^{\circ} \mathrm{C}$. Hereafter, samples annealed at different temperatures are denoted as Ni-P/SiC-50, Ni-P/SiC-350, Ni$\mathrm{P} / \mathrm{SiC}-400, \mathrm{Ni}-\mathrm{P} / \mathrm{SiC}-450$ and $\mathrm{Ni}-\mathrm{P} / \mathrm{SiC}-500$, respectively. During the heat treatment, a constant heating rate of $5{ }^{\circ} \mathrm{C} / \mathrm{min}$ was maintained until the designated temperature was reached, and all samples were isothermally annealed at the target temperature for 1 hour before cooling naturally to room temperature. As the isothermal annealing was conducted in an electric furnace followed by aircooling, a thin oxide layer formed on the top surface of the coatings. In order to remove the residual surface oxides, after the heat treatments the samples were polished by using a $0.3 \mu \mathrm{m} \mathrm{Al}{ }_{2} \mathrm{O}_{3}$ colloidal solution for 5 minutes.

\subsection{Characterization of microstructure and mechanical properties}

The surface morphology of Ni-P/SiC coatings after polishing was examined by using a FEGSEM (JEOL-JSM-6500F, Japan) while the chemical composition of the deposits was measured by using energy dispersive X-ray spectroscopy (FEI Quanta 200, Netherland). Moreover, SiC 
nanoparticles were observed by SEM (Zeiss). Microstructural analyses were carried out by X-ray diffraction (XRD) with a $\mathrm{Cu}-\mathrm{K}_{\alpha}$ radiation (Siemens D-5000). XRD data were recorded for $2 \theta$ ranging between $20^{\circ}-100^{\circ}$ with a scan step size of $0.05^{\circ}$ at a scan rate of $5^{\circ} / \mathrm{min}$. A nanoindenter (Micromaterials, Wrexham, UK) equipped with a diamond Berkovich tip was used to measure the mechanical properties of $\mathrm{Ni}-\mathrm{P} / \mathrm{SiC}$ coatings. In order to minimize substrate effects a penetration depth of $500 \mathrm{~nm}$ (less than $1 \%$ of coatings thickness) was used. At least 10 indents were performed on each coating for statistical analyses. Hardness $(H)$ and reduced elastic modulus $\left(E_{\mathrm{r}}\right)$ were calculated from the load-displacement curves according to the procedure outlined by Oliver and Pharr

\subsection{Tribological properties}

A reciprocating tribometer (TE77, Phoenix Tribology, Ltd.) was used to evaluate the tribological properties of Ni-P/SiC coatings. Based on the potential application of Ni-P/SiC coatings on crankshaft and piston ring, 52100 steel balls $(\varnothing 6 \mathrm{~mm})$ as a material for making linkage (against crankshaft) and cylinder (against piston ring) were used as counterparts in this study. In order to obtain a steady friction coefficient after the running-in stage and before coatings failure, the load and frequency were kept at $10 \mathrm{~N}$ and $5 \mathrm{~Hz}$, respectively over a stroke of $10 \mathrm{~mm}$ and for a sliding time of 1 hour. Accordingly, a line velocity of $0.1 \mathrm{~m} / \mathrm{s}$ and a total sliding distance of $360 \mathrm{~m}$ were covered. To ensure the validity of collected frictional data, two tribotests were carried out for each coating, while a third test was carried out when the relative error was over $5 \%$.

After tribotests, the wear scars on counterparts and coatings were measured by a 3D optical microscope (Infinite Focus, Alicona, UK). The wear volume of the balls was assessed using Eq. (1), while the wear volume of the coatings was calculated by taking into account the cross-section $(A)$ and the length $(L)$ of wear track.

$$
V=\frac{\pi d^{4}}{64 \mathrm{R}}
$$

In Eq. (1), $\mathrm{d}$ and $\mathrm{R}$ are the diameter of wear scar and the radius of the steel ball, respectively. Moreover, the morphology of wear track was observed by FEG-SEM (JEOL-JSM-6500F, Japan), and its composition was analyzed using EDS (Inca Energy 350, Oxford, UK). 


\section{Results and discussions}

\subsection{Microstructure}

SiC particles exhibited a spherical shape (Fig.1a) and a cubic crystalline structure (Fig.1b), which demonstrates their high purity $(97.5 \%)$. As seen in Fig.2a, all of the Ni-P/SiC coatings exhibited two main diffraction peaks attributed to $\mathrm{Ni}(111)$ and $\mathrm{Ni}(222)$ around $44.43^{\circ}$ and $98.33^{\circ}$, respectively (reference: JCPDS 04-0850). The intensity of these peaks increased significantly after annealing, thus suggesting a higher degree of crystallinity for $\mathrm{Ni}$ in $\mathrm{Ni}-\mathrm{P} / \mathrm{SiC}$ coatings. Accordingly, the crystallite size calculated from the Ni (111) peak by using the Scherrer's formula also increased in relation to the annealing temperature (Fig.2b). On the other hand, after annealing a weak peak $\left(2 \theta \sim 60.16^{\circ}\right)$ attributed to $\mathrm{A}_{3} \mathrm{P}$ phase appeared in the XRD pattern for the Ni-P/SiC-350 coating, while the XRD pattern was more densely populated by peaks attributed to $\mathrm{Ni}_{3} \mathrm{P}$ when the annealing temperature exceeded $350^{\circ} \mathrm{C}$ (Fig.2a). Structural properties of Ni-P/SiC-50 and Ni-P/SiC-450 coatings were extracted from the XRD patterns by using a Difrac ${ }^{\circledR}$ plus Eva software and listed in Table 3. In spite of a high number of $\mathrm{Ni}_{3} \mathrm{P}$ peaks observed in the diffractograms, the fraction of $\mathrm{Ni}_{3} \mathrm{P}$ was still limited due to the low concentration of phosphorus in Ni-P/SiC coatings (5.9 wt\%). The surface morphology of polished Ni-P/SiC coatings (Fig.3) became smoother with increasing annealing temperature, thus affecting the frictional behavior of the coatings, as will be discussed in the following sections.

\subsection{Characterization of mechanical property}

Hardness $(H)$ and reduced elastic modulus $\left(E_{\mathrm{r}}\right)$ of Ni-P/SiC coatings were calculated from the load-displacement curves after that these were corrected by taking into account thermal drift and frame compliance. Table 4 summarizes calculated mechanical properties. Annealed coatings exhibited a higher average hardness $(7.1 \pm 0.6-8.2 \pm 0.5 \mathrm{GPa})$ compared to the Ni-P/SiC-50 coating $(6.3 \pm 0.3 \mathrm{GPa})$. The hardness increase is attributed to the formation of a hard $\mathrm{Ni}_{3} \mathrm{P}$ phase [33]. Nevertheless, the hardness of Ni-P/SiC coatings decreased gradually from $8.2 \mathrm{GPa}$ to $7.1 \mathrm{GPa}$ as the annealing temperature was increased from 400 to $500{ }^{\circ} \mathrm{C}$. The observed decrease in hardness is 
attributed to the increasing grain size of the $\mathrm{Ni}$ (111) phase according to the Hall-Petch effect [34]. Wear resistance is often correlated to mechanical parameters such as $H / E_{\mathrm{r}}$ and $H^{3} / E_{\mathrm{r}}^{2}$ ratios, which provide simultaneous information about resistance to plastic deformation and elastic properties of materials [35]. Based on these parameters (Tab. 4), the coating annealed at $400{ }^{\circ} \mathrm{C}$ is expected to exhibit the best tribological performance.

\subsection{Frictional properties}

Fig. 4a shows some representative friction curves measured on coatings annealed at different temperatures. It is seen that the friction coefficient of coatings annealed at temperatures $\leq 450{ }^{\circ} \mathrm{C}$ gradually decreased to a lower value in the steady-state regime. On the other hand, the friction coefficient measured for the $\mathrm{Ni}-\mathrm{P} / \mathrm{SiC}-500$ coating slightly increased before to reach a steady-state value. These differences were attributed to the lower surface roughness exhibited by the coating annealed at $500{ }^{\circ} \mathrm{C}$ (Fig.3). In addition, the running-in period $\left(P_{\mathrm{r}}\right)$ for Ni-P/SiC-450 and Ni-P/SiC500 coatings (around $300 \mathrm{~s}$ ) was significantly shorter than that found for Ni-P/SiC-50 (900 s) and NiP/SiC-350 (1200 s) coatings. This is attributed to their smoother surface morphology, which reduced the time needed to remove large asperities. In order to characterize the friction behavior of Ni-P/SiC coatings, a mean-steady friction value $\left(\mu_{\mathrm{m}}\right)$ was calculated as average over the steady-stage regime (see Fig.4b). The as-plated Ni-P/SiC-50 coating exhibited a $\mu_{\mathrm{m}}$ of 0.54 , while a slight increase $(\sim 0.55)$

occurred after annealing at $350{ }^{\circ} \mathrm{C}$. For higher annealing temperatures in the range of $350-500{ }^{\circ} \mathrm{C}, \mu_{\mathrm{m}}$ gradually decreased from 0.55 to 0.51 .

XRD patterns indicated that, for annealing temperatures above $350{ }^{\circ} \mathrm{C}$, the $\mathrm{Ni}_{3} \mathrm{P}$ phase gradually formed in coatings. Compared with the oxidation reaction of $\mathrm{Ni}-\mathrm{P} / \mathrm{SiC}-50$ and $\mathrm{Ni}-\mathrm{P} / \mathrm{SiC}-350$ coatings (Eq. (2)), Ni-P/SiC-400, Ni-P-/SiC-450 and Ni-P/SiC-500 coatings experienced the oxidation reaction given as Eq. (3).

$$
\begin{gathered}
4 \mathrm{Ni}+3 \mathrm{O}_{2}=2 \mathrm{Ni}_{2} \mathrm{O}_{3} \\
\Delta G_{\mathrm{f}}^{298}=-287.6 \mathrm{~kJ} \cdot \mathrm{mol}^{-1} \\
2 \mathrm{Ni}_{3} \mathrm{P}+7 \mathrm{O}_{2}=3 \mathrm{Ni}_{2} \mathrm{O}_{3}+\mathrm{P}_{2} \mathrm{O}_{5}
\end{gathered}
$$




$$
\begin{gathered}
\Delta G_{\mathrm{f}}^{298}=-1364.7 \mathrm{~kJ} \cdot \mathrm{mol}^{-1} \\
\mathrm{P}_{2} \mathrm{O}_{5}+3 \mathrm{H}_{2} \mathrm{O}=2 \mathrm{H}_{3} \mathrm{PO}_{4} \\
\Delta G_{\mathrm{f}}^{298}=-144.1 \mathrm{~kJ} \cdot \mathrm{mol}^{-1}
\end{gathered}
$$

As a generation of Eq. (3), $\mathrm{P}_{2} \mathrm{O}_{5}$ is extremely unstable and therefore can easily absorb water from the environment to form orthophosphoric acid $\left(\mathrm{H}_{3} \mathrm{PO}_{4}\right)$ as determined in Eq. (4). Based on the literature, $\mathrm{H}_{3} \mathrm{PO}_{4}$ could have a significant effect on tribological behavior [36-38]. For instance, $\mathrm{TiN} / \mathrm{Al}_{2} \mathrm{O}_{3}$ tribopair presented a low friction coefficient of 0.1 in $\mathrm{H}_{3} \mathrm{PO}_{4}$ compared to that measured in demineralised water (0.4), which was attributed to a lubricant gel containing Fe-P-O [36]. Likewise, Luo's group [37, 38] found a superlubricity phenomenon of $\mathrm{Si}_{3} \mathrm{~N}_{4} /$ glass tribopair with a friction coefficient of 0.004 measured in aqueous solution of $\mathrm{H}_{3} \mathrm{PO}_{4}(\mathrm{pH}=1.5)$. It was concluded that the electrical double layer effect and the hydration effect on the positive charged surface caused the observed superlubrication. In our study, the formation of $\mathrm{H}_{3} \mathrm{PO}_{4}$ during sliding, especially in coatings annealed at the temperatures above $400^{\circ} \mathrm{C}$, was responsible for the lower friction coefficient (see Fig. 4b). In particular, the $\mathrm{Ni}-\mathrm{P} / \mathrm{SiC}-500$ coating with the highest $\mathrm{Ni}_{3} \mathrm{P}$ content exhibited the lowest friction coefficient (0.51). The lower friction coefficient measured for Ni-P/SiC-450 and Ni-P/SiC-500 coatings was also attributed to the better surface quality achieved after polishing (Fig.3d-e). A similar result was reported in elsewhere [10].

\subsection{Wear mechanisms}

The wear rate $\left(W_{\mathrm{r}}\right)$ measured on Ni-P/SiC coatings (Fig.5a) exhibited a similar trend as that found for $\mu_{\mathrm{m}}$ (Fig. $\left.4 \mathrm{~b}\right)$. In particular, Ni-P/SiC-350 coating exhibited the highest wear rate $\left(6.1 \times 10^{-5}\right.$ $\mathrm{mm}^{3} / \mathrm{Nm}$ ) while $\mathrm{Ni}-\mathrm{P} / \mathrm{SiC}-500$ coating presented the strongest wear resistance with the lowest wear rate of $7.8 \times 10^{-6} \mathrm{~mm}^{3} / \mathrm{Nm}$. Generally, the wear resistance of coatings is proportional to the $H$ as well as to $H / E_{\mathrm{r}}$ and $H^{3} / E_{\mathrm{r}}^{2}$ ratios. However, Ni-P/SiC-500 with the lowest hardness, instead of Ni-P/SiC400 with superior mechanical properties, exhibited the strongest wear resistance. As referred above, the $\mathrm{H}_{3} \mathrm{PO}_{4}$ produced from the tribochemical reaction not only reduced friction coefficient, but also contributed to the formation of Fe-P-O gel, thus preventing further wear. Therefore, a higher $\mathrm{Ni}_{3} \mathrm{P}$ 
content in Ni-P/SiC-500 coating resulted in a larger formation of $\mathrm{H}_{3} \mathrm{PO}_{4}$ with a subsequent reduction in both friction and wear. In addition, the Fe-P-O gel also contributed at protecting the counterparts, and therefore the wear rate of 52100 ball sliding against Ni-P/SiC-500 coating was only $2.9 \times 10^{-7}$ $\mathrm{mm}^{3} / \mathrm{Nm}$. This wear rate was one order of magnitude lower (Fig.5b) compared to that found on balls used against coatings annealed at 350,400 and $450{ }^{\circ} \mathrm{C}\left(2.2 \sim 4.3 \times 10^{-6} \mathrm{~mm}^{3} / \mathrm{Nm}\right)$.

On the other hand, during reciprocating sliding tests, wear debris were difficult to be removed from the wear track immediately and often they were pressed to form oxide films on the sliding surface. This is evident from the EDS measurements reported in Fig.6. All the wear tracks in this study were oxidized at different levels. Oxides were observed on the wear tracks of Ni-P/SiC-50 and Ni-P/SiC-350 coatings, while little oxides were found on the wear tracks of Ni-P/SiC-450 and NiP/SiC-500 coatings (Fig.7). As a result, the roughness ( $\mathrm{Ra}$ ) of the wear tracks on Ni-P/SiC-50 and NiP/SiC-350 coatings $(7.86 \sim 8.82 \mu \mathrm{m})$ were higher than that measured on the coatings annealed at 400 , 450 and $500{ }^{\circ} \mathrm{C}(2.15 \sim 5.71 \mu \mathrm{m})$. Moreover, according to EDS analysis in Fig.6b', the wear debris on Ni-P/SiC-350 coating consisted of nickel and iron oxides, which instead were absent on the wear track of Ni-P/SiC-50 coating. Iron oxides were found to further deteriorate the contact surface, thus leading to the highest wear rate and $\mathrm{Ra}(8.82 \mu \mathrm{m})$ for Ni-P/SiC-350 coating. For higher annealing temperatures $\left(400-500{ }^{\circ} \mathrm{C}\right)$, the wear track of individual coatings became smoother due to the tribochemical reaction mentioned above. In particular, the Ni-P/SiC-500 coating exhibited a wear track with the lowest oxygen content $(9.1$ at.\%), thus suggesting less oxides adhered on the sliding surface. Consequently, the smoother interface $(R \mathrm{a}=2.15 \mu \mathrm{m})$ and the fewer oxides found on the wear track of the Ni-P/SiC-500 coating contributed to lower the wear rate.

\section{Conclusions}

Structural, mechanical and tribological properties of $\mathrm{Ni}-\mathrm{P} / \mathrm{SiC}$ nanocomposite coatings were investigated in relation to the post-deposition heat treatment and in particular as a function of the annealing temperature. Conclusions are drawn as follows:

(1) Regardless of the annealing temperature in the range of $350-500{ }^{\circ} \mathrm{C}$, a hard $\mathrm{Ni}_{3} \mathrm{P}$ phase 
formed in annealed coatings, thus causing an increase in hardness ranging from $7.1 \pm 0.6$ to $8.2 \pm 0.5$ GPa compared to the as-plated coating $(6.3 \pm 0.3 \mathrm{GPa})$.

(2) Despite of the highest hardness (8.2 GPa), Ni-P/SiC coating annealed at $350{ }^{\circ} \mathrm{C}$ presented the worst tribological properties $\left(\mu=0.55\right.$ and $\left.W_{\mathrm{r}}=6.1 \times 10^{-5} \mathrm{~mm}^{3} / \mathrm{Nm}\right)$ because of its rougher surface morphology and scarce formation of solid lubricant $\left(\mathrm{H}_{3} \mathrm{PO}_{4}\right)$ from the tribochemical reaction owing to the lower $\mathrm{Ni}_{3} \mathrm{P}$ content compared to the other coatings.

(3) The lubricating effect associated with the formation of $\mathrm{H}_{3} \mathrm{PO}_{4}$ in Ni-P/SiC coatings annealed at temperatures $\geq 400{ }^{\circ} \mathrm{C}$, contributed to lower friction coefficient $(0.51-0.54)$ and wear rate $\left(4.3 \times 10^{-}\right.$ ${ }^{5}-7.8 \times 10^{-6} \mathrm{~mm}^{3} / \mathrm{Nm}$ ), while higher values were found for lower annealing temperatures.

(4) In spite of the lower hardness $(7.1 \mathrm{GPa})$ compared to the other coatings, Ni-P/SiC-500 exhibited the lowest friction coefficient $(0.51)$ and wear rate $\left(7.8 \times 10^{-6} \mathrm{~mm}^{3} / \mathrm{Nm}\right)$ owing to a sufficient formation of solid lubrication $\left(\mathrm{H}_{3} \mathrm{PO}_{4}\right)$ and to its better surface quality.

\section{Acknowledgement}

The research leading to these results has received funding from the European Union's Seventh Framework Research for SME Associations Programme under grant agreement No. 606110 (HardAlt).

\section{Reference:}

[1] K.G. Budinski, M.K. Budinski, Engineering Materials: Properties and Selection, Ninth ed., Prentice Hall, New York, 2010.

[2] B. Sonntag, V. Sundaram, Substitution of Cr (VI)-containing coatings by the European automobile industry. Indian Surf. Finish. 1 (2004) 15-26.

[3] M.D. Cohen, M. Costa, Chromium, in: M. Lippmann, Environmental Toxicants: Human Exposures and Their Health Effects, Second ed., Wiley, New York, 2000, pp. 173-191.

[4] B. Panja, P. Sahoo, Wear behavior of electroless Ni-P coatings in brine solution and optimization of coating parameters. Procedia Technol. 14 (2014) 173-180.

[5] R. Elansezhian, B. Ramamoorthy, P. K. Nair, Effect of surfactants on the mechanical properties of electroless (Ni-P) coating. Surf. Coat. Technol. 203 (2008) 709-712.

[6] W.L. Liu, S.H. Hsieh, T.K. Tsai, W.J. Chen, S.S. Wu, Temperature and pH dependence of the electroless Ni-P deposition on silicon. Thin Solid Films 510 (2006) 102-106.

[7] J.D. Lin, C.L. Kuo, C.J. Hsia, The influence of microwave-assisted hydrogen plasma treatment on electroless Ni-P coatings. Mater. Chem. Phys. 137 (2013) 848-858. 
[8] M. Novak, D. Vojtech, P. Novak, T. Vitu, Tribological properties of heat-treated electroless Ni-P coatings on AZ91 alloy. Appl. Surf. Sci. 257 (2011) 9982-9985.

[9] S.S. Zhang, K.J. Han, L. Cheng, The effect of SiC particles added in electroless Ni-P plating solution on the properties of composite coatings. Surf. Coat. Technol. 202 (2008) 2807-2812.

[10] M. Franco, W. Sha, S. Malinov, H. Liu, Micro-scale wear characteristics of electroless Ni-P/SiC composite coating under two different sliding conditions. Wear 317 (2014) 254-264.

[11] I.R. Mafi, C. Dehghanian, Studying the effects of the addition of TiN nanoparticles to Ni-P electroless coatings. Appl. Surf. Sci. 258 (2011) 1876-1880.

[12] S.M.A. Shibli, V.S. Dilimon, Effect of phosphorous content and $\mathrm{TiO}_{2}$-reinforcement on Ni-P electroless plates for hydrogen evolution reaction. Int. J. Hydrogen Energy 32 (2007) 1694-1700.

[13] S. Sadreddini, Z. Salehi, H. Rassaie, Characterization of Ni-P-SiO${ }_{2}$ nano-composite coating on magnesium. Appl. Surf. Sci. 324 (2015) 393-398.

[14] Z.A. Hamid, S.A.E. Badry, A.A. Aal, Electroless deposition and characterization of Ni-P-WC composite alloys. Surf. Coat. Technol. 201 (2007) 5948-5953.

[15] S. Alirezaei, S.M. Monirvaghefi, M. Salehi, A. Saatchi, Wear behavior of Ni-P and Ni-P- $\mathrm{Al}_{2} \mathrm{O}_{3}$ electroless coatings. Wear 262 (2007) 978-985.

[16] M.E. Hosseinabadi, K.A. Dorcheh, S.M.M. Vaghefi, Wear behavior of electroless Ni-P-B 4 C composite coatings. Wear 260 (2006) 123-127.

[17] M. Alishahi, S.M. Monirvaghefi, A. Saatchi, S.M. Hosseini, The effect of carbon nanotubes on the corrosion and tribological behavior of electroless Ni-P-CNT composite coating. Appl. Surf. Sci. 258 (2012) 2439-2446.

[18] I.R. Aslanyan, J.P. Bonino, J.P. Celis, Effect of reinforcing submicron SiC particles on the wear of electrolytic Ni-P coatings Part 1: Uni-directional sliding. Surf. Coat. Technol. 200 (2006) 2909-2916.

[19] X.T. Yuan, D.B. Sun, H.Y. Yu, Y. Wang, Effect of nano-SiC particles on the corrosion resistance of Ni-PSiC composite coatings. Int. J. Miner. Metall. Mater. 16 (2009) 444-451.

[20] A. Zoikis-Karathanasis, E.A. Pavlatou, N. Spyrellis, Pulse electrodeposition of Ni-P matrix composite coatings reinforced by SiC particles. J. Alloys Compd. 494 (2010) 396-403.

[21] H.L. Wang, L.Y. Liu, Y. Dou, W.Z. Zhang, W.F. Jiang, Preparation and corrosion resistance of electroless Ni-P/SiC functionally gradient coatings on AZ91D magnesium alloy. Appl. Surf. Sci. 286 (2013) 319-327.

[22] C.F. Malfatti, H.M. Veit, T.L. Menezes, J. Zoppas Ferreira, J.S. Rodriguês, J.P. Bonino, The surfactant addition effect in the elaboration of electrodeposited Ni-P-SiC composite coatings. Surf. Coat. Technol. 201 (2007) 6318-6324.

[23] Y.T. Wu, H.Z. Liu, B. Shen, L. Liu, W.B. Hu, The friction and wear of electroless Ni-P matrix with PTFE and/or SiC particles composite. Tribol. Int. 39 (2006) 553-559.

[24] C. F. Malfatti, H. M. Veit, C. B. Santos, M. Metzner, H. Hololeczek, J.P. Bonino, Heat treated Ni-P-SiC composite coatings: elaboration and tribocorrosion behaviour in $\mathrm{NaCl}$ solution. Tribol. Int. 36 (2009) 165-173. [25] I. R. Aslanyan, J.P. Celis, L. Sh. Shuster, Effect of reinforcing submicron SiC particles on the wear process of electrolytic Ni-P coatings. J. Frict. Wear 31 (2010) 341-348. 
[26] A. Amell, C. Muller, M. Sarret, Influence of fluorosurfactants on the codeposition of ceramic nanoparticles and the morphology of electroless Ni-P coatings. Surf. Coat. Technol. 205 (2010) 356-362.

[27] S.R. Allahkaram, M. H. Nazari, S. Mamaghani, A. Zarebidaki, Characterization and corrosion behavior of electroless Ni-P/nano-SiC coating inside the $\mathrm{CO}_{2}$ containing media in the presence of acetic acid. Mater. Des. 32 (2011) 750-755.

[28] A. Farzaneh, M. Mohammadi, M. Ehteshamzadeh, F. Mohammadi, Electrochemical and structural properties of electroless Ni-P-SiC nanocomposite coatings, Appl. Surf. Sci. 276 (2013) 697-704.

[29] F. Bigdeli, S.R. Allahkaram, An investigation on corrosion resistance of as-applied and heat treated NiP/nano SiC coatings, Mater. Des. 30(10) (2009) 4450-4453.

[30] C.J. Lin, K.C. Chen, J.L. He, The cavitation erosion behavior of electroless Ni-P-SiC composite coating. Wear 261 (2006) 1390-1396.

[31] M. Sarret, C. Müller, A. Amell, Electroless Ni-P micro- and nano-composite coatings. Surf. Coat. Technol. 201 (2006) 389-395.

[32] R. Soleimani, F. Mahboubi, M. Kazemi, S.Y. Arman, Corrosion and tribological behaviour of electroless Ni-P/nano-SiC composite coating on aluminium 6061, Surf. Eng. 31(9) (2015) 714-721.

[33] D. Nava, C.E. Dávalos, A. Martínez-Hernández, F. Manríquez, Y. Meas, R. Ortega-Borges, J.J. PérezBueno, G. Trejo, Effects of heat treatment on the tribological and corrosion properties of electrodeposited NiP alloys. Int. J. Electrochem. Sci. 8 (2013) 2670-2681.

[34] M.A. Meyers, A. Mishra, D.J. Benson, Mechanical properties of nanocrystalline materials. Prog. Mater. Sci. 51 (2006) 427-556.

[35] N.A. Sakharova, J.V. Fernandes, M.C. Oliveira, J.M. Antunes, Influence of ductile interlayers on mechanical behaviour of hard coatings under depth-sensing indentation: a numerical study on TiAlN. J. Mater. Sci. 45 (2010) 3812-3823.

[36] E. Wit, D. Drees, P.Q. Wu, J.P. Celis, Lubricating reaction products on TiN coatings during sliding wear in phosphoric acid. Surf. Coat. Technol. 135 (2000) 8-13.

[37] J.J. Li, C.H. Zhang, J.B. Luo, Superlubricity behavior with phosphoric acid-water network induced by rubbing. Langmuir 27 (2011) 9413-9417.

[38] J.J. Li, C.H. Zhang, L. Sun, X.C. Lu, J.B. Luo, Tribochemistry and superlubricity induced by hydrogen ions. Langmuir 28 (2012) 15816-15823. 

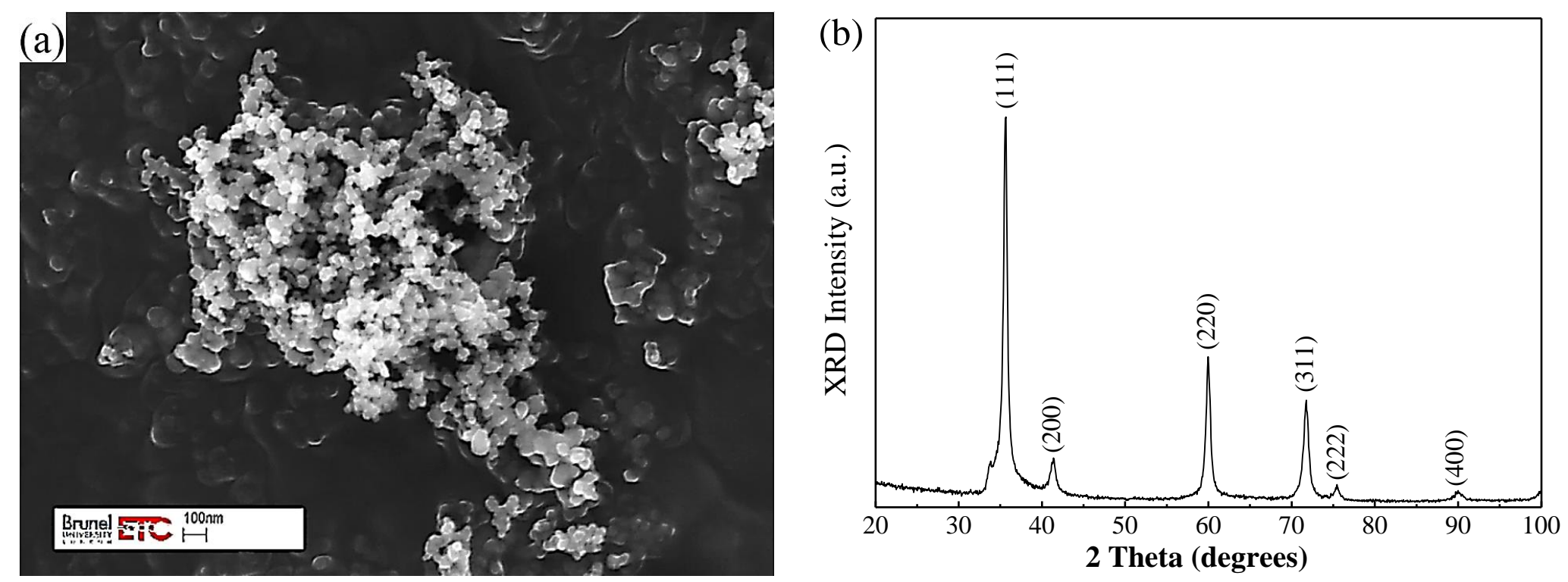

Fig.1 (a) FESEM image (b) XRD spectrum of $\beta$-SiC particles 

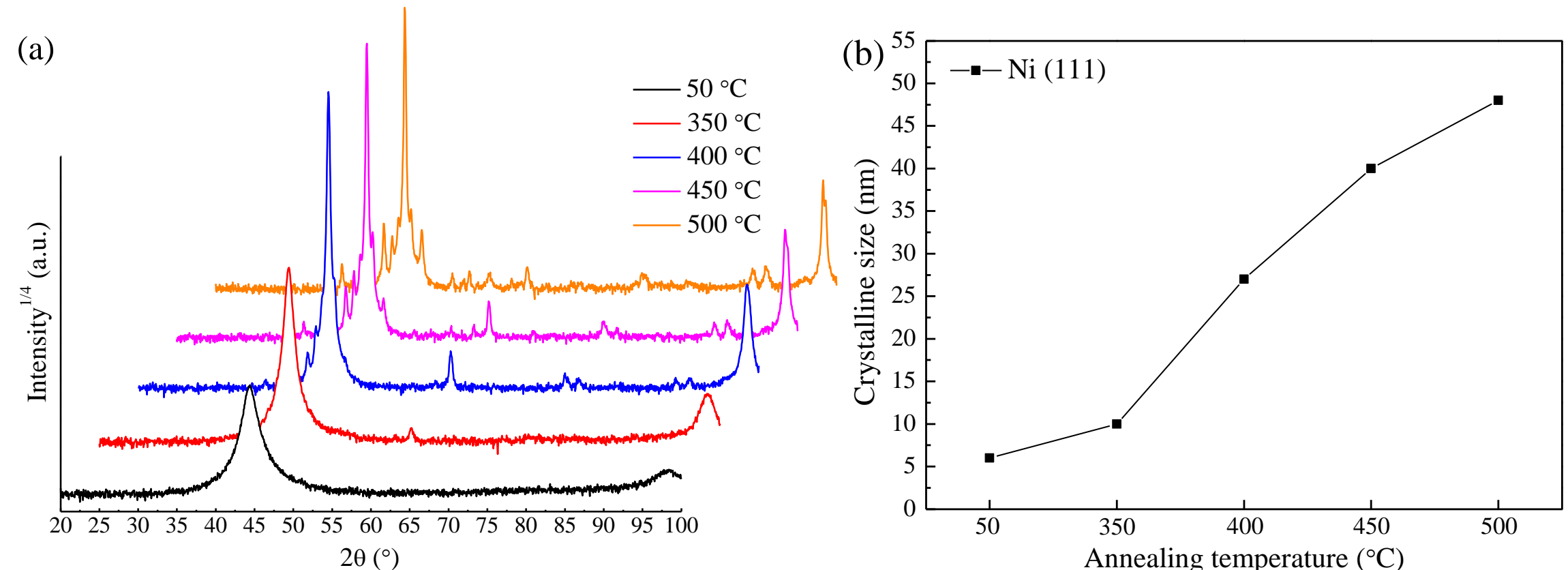

Fig.2 (a) XRD spectra of Ni-P/SiC coatings (b) Crystalline size of Ni (111) at different annealing temperatures 


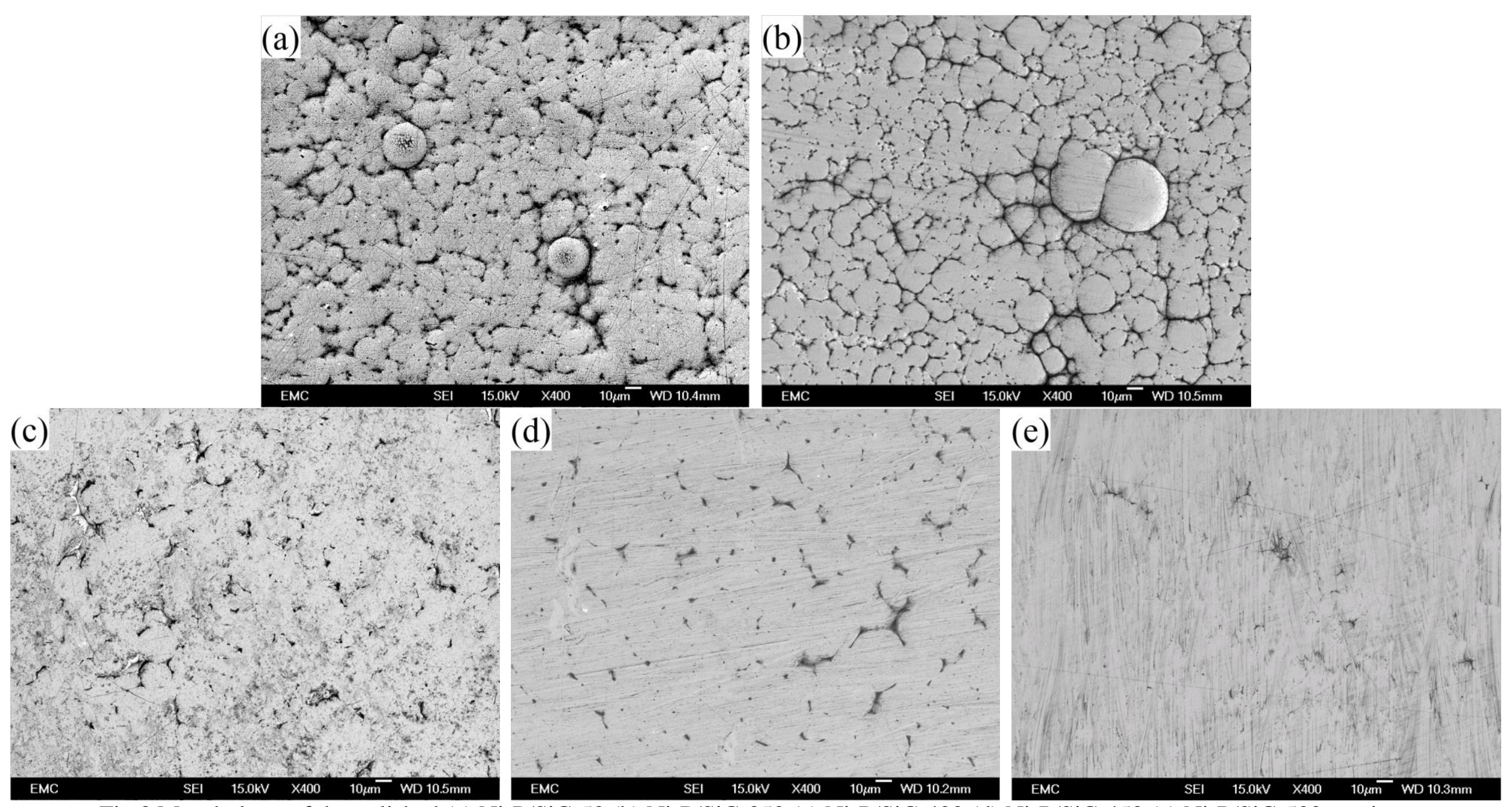

Fig.3 Morphology of the polished (a) Ni-P/SiC-50 (b) Ni-P/SiC-350 (c) Ni-P/SiC-400 (d) Ni-P/SiC-450 (e) Ni-P/SiC-500 coatings 

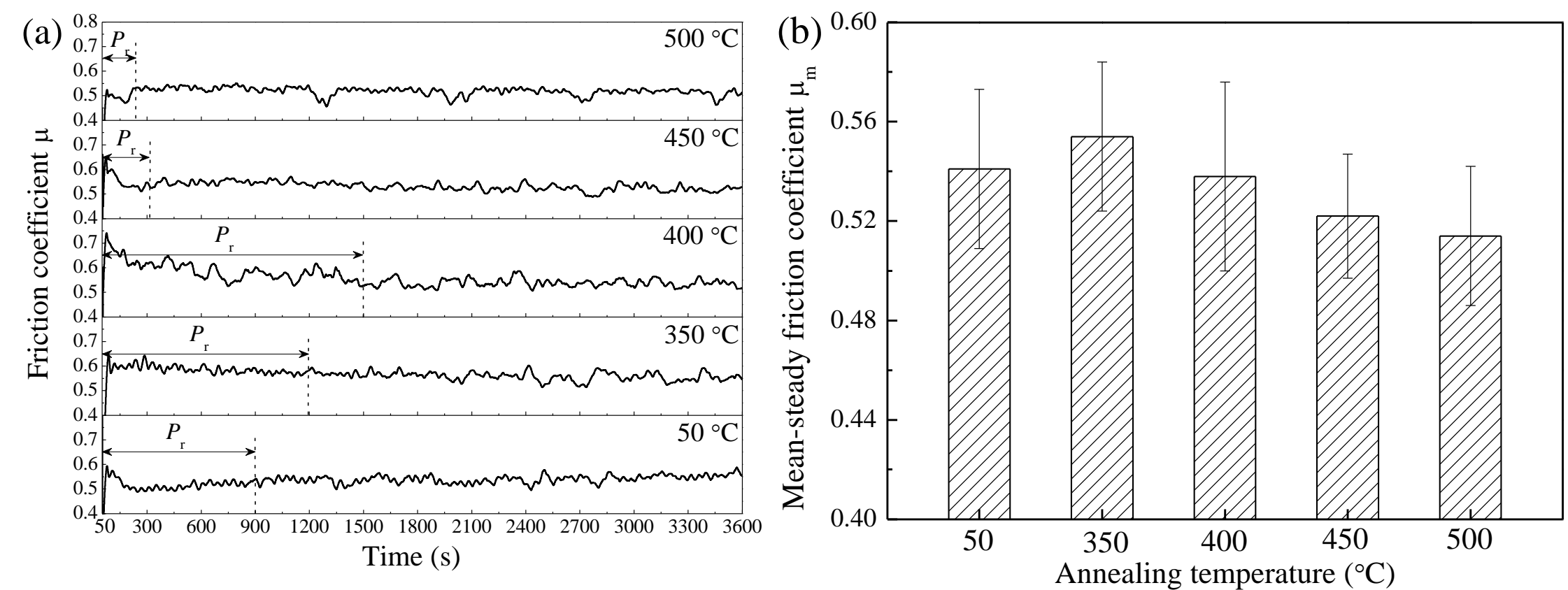

Fig.4 (a) Friction behavior (b) Mean-steady friction coefficient of Ni-P/SiC coatings at different annealing temperatures 

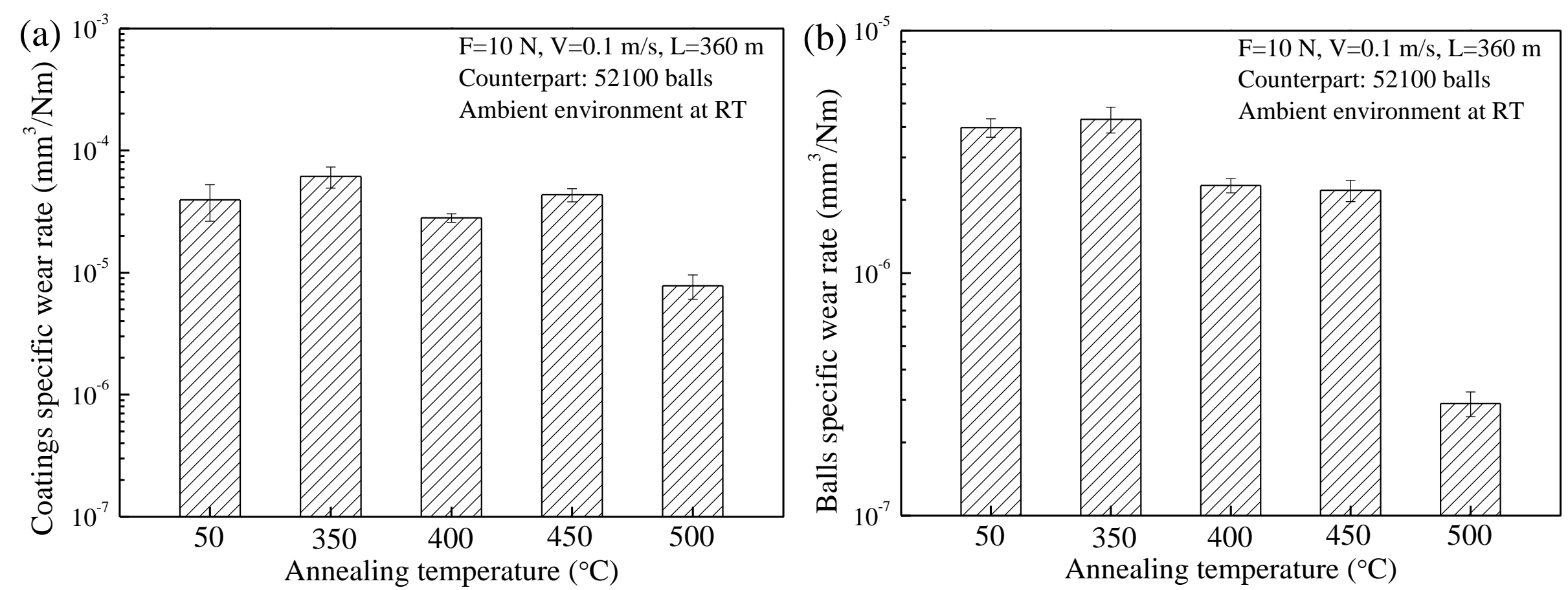

Fig.5 Specific wear rates of (a) Ni-P/SiC coatings and (b) 52100 balls at different annealing temperatures 

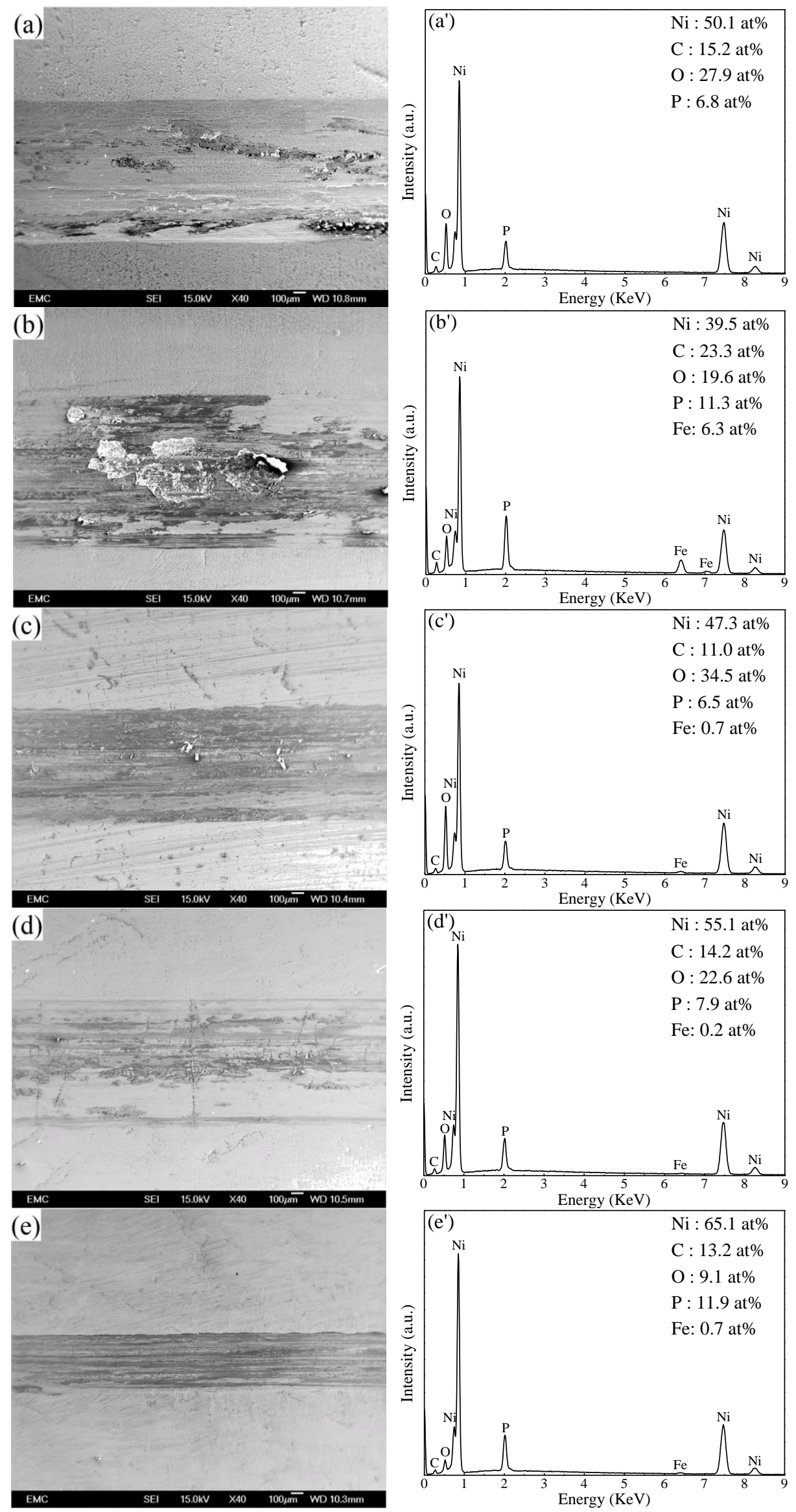

Fig.6 Overviews of wear tracks and EDS analyses on (a)(a') Ni-P/SiC-50 (b)(b') Ni-P/SiC-350 (c)(c') Ni-P/SiC-400 (d)(d') Ni-P/SiC-450 (e)(e') Ni-P/SiC-500 coatings 

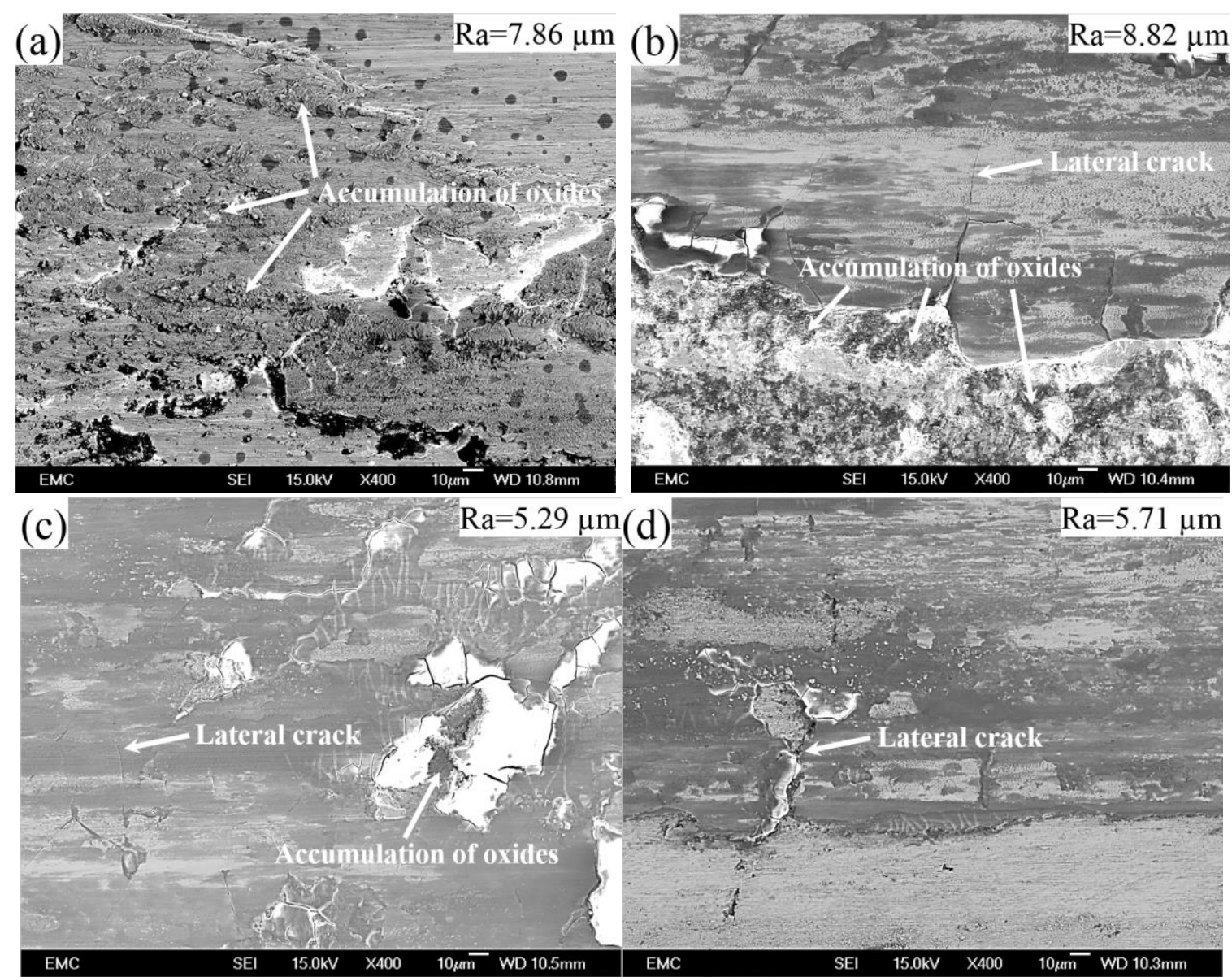

(e)

$\mathrm{Ra}=2.15 \mu \mathrm{m}$

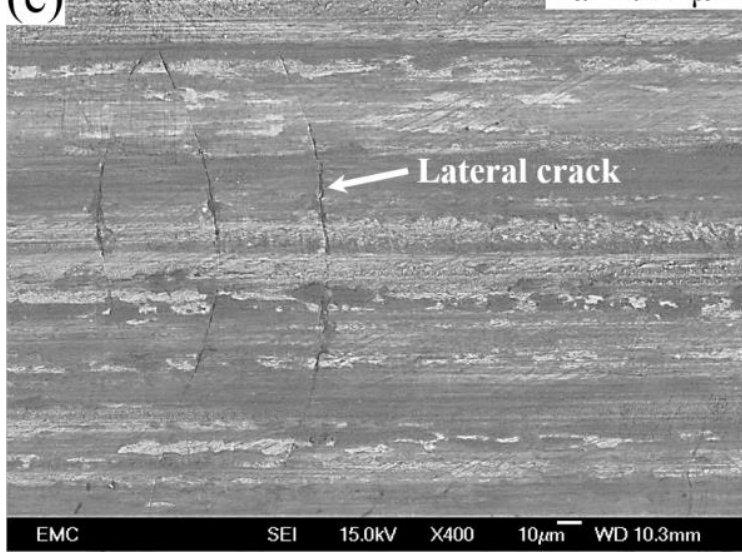

Fig.7 SEM images of partial wear tracks on (a) Ni-P/SiC-50 (b) Ni-P/SiC-350 (c) Ni-P/SiC-400 (d) $\mathrm{Ni}-\mathrm{P} / \mathrm{SiC}-450$ (e) Ni-P/SiC-500 coatings 
Table 1 Mechanical properties of Ni-P composite coatings reinforced by different particles

\begin{tabular}{cccccc}
\hline Reference & Particles & Loading (g/L) & $\begin{array}{c}\text { Hardness of Ni-P } \\
(\mathbf{H v})\end{array}$ & $\begin{array}{c}\text { Hardness of Ni-P } \\
\text { composite (Hv) }\end{array}$ & $\begin{array}{c}\Delta \text { of hardness } \\
(\mathbf{H v})\end{array}$ \\
\hline Zhang et al. [9] & $\mathrm{SiC}$ & 12.0 & 530 & 809 & 279 \\
Mafi et al. [11] & $\mathrm{TiN}$ & 1.0 & 561 & 660 & 59 \\
Shibli et al. [12] & $\mathrm{TiO}_{2}$ & 12.0 & 429 & 429 & 124 \\
Sadreddini et al. [13] & $\mathrm{SiO}_{2}$ & 12.5 & 342 & 650 & 87 \\
Hamid et al. [14] & $\mathrm{WC}$ & 12.5 & 465 & 700 & 185 \\
Alirezaei et al. [15] & $\mathrm{Al}_{2} \mathrm{O}_{3}$ & 15.0 & 475 & 720 & 225 \\
Hosseinabadi et al. [16] & $\mathrm{B}_{4} \mathrm{C}$ & 4.0 & 640 & 800 & 80 \\
Alishahi et al. [17] & $\mathrm{CNT}$ & 2.0 & 538 & & 262 \\
\hline
\end{tabular}


Table 2 Electro-deposition conditions of Ni-P/SiC coatings

\begin{tabular}{cc}
\hline Temperature & $50 \pm 2{ }^{\circ} \mathrm{C}$ \\
$\mathrm{pH}$ & $1 \pm 0.2$ \\
SiC load & $5 \mathrm{~g} / \mathrm{L}$ \\
Current density & $20 \mathrm{Adm}^{-2}$ \\
Substrate & Steel platelet \\
Anode & Nickel (S) \\
\hline
\end{tabular}


Table 3 Phase conditions of the as-plated Ni-P/SiC coating and Ni-P/SiC coating annealed at $450{ }^{\circ} \mathrm{C}$

\begin{tabular}{|c|c|c|c|c|c|c|c|c|c|c|c|c|c|c|c|c|c|}
\hline Coatings & \multicolumn{17}{|c|}{ Ni-P/SiC-50 } \\
\hline 2 Theta $\left(^{\circ}\right)$ & -- & -- & -- & -- & 44.43 & -- & -- & -- & -- & -- & -- & -- & -- & -- & -- & -- & 98.33 \\
\hline Intensity (\%) & -- & -- & -- & -- & 100 & -- & -- & -- & -- & -- & -- & -- & -- & -- & -- & -- & 4.5 \\
\hline Phase & -- & -- & -- & -- & $\mathrm{Ni}$ & -- & -- & -- & -- & -- & -- & -- & -- & -- & -- & -- & $\mathrm{Ni}$ \\
\hline hkl & -- & -- & -- & -- & 111 & -- & -- & -- & -- & -- & -- & -- & -- & -- & -- & -- & 222 \\
\hline Coatings & \multicolumn{17}{|c|}{ Ni-P/SiC-450 } \\
\hline 2 Theta $\left(^{\circ}\right)$ & 36.38 & 41.80 & 42.80 & 43.68 & 44.46 & 45.22 & 46.66 & 50.54 & 55.39 & 58.27 & 60.16 & 66.00 & 74.97 & 76.74 & 89.24 & 90.89 & 98.42 \\
\hline Intensity (\%) & 0.1 & 0.7 & 1.3 & 2.2 & 100 & 4.1 & 0.4 & 0.1 & 0.1 & 0.1 & 0.4 & 0.1 & 0.1 & 0.1 & 0.1 & 0.1 & 4.4 \\
\hline Phase & $\mathrm{Ni}_{3} \mathrm{P}$ & $\mathrm{Ni}_{3} \mathrm{P}$ & $\mathrm{Ni}_{3} \mathrm{P}$ & $\mathrm{Ni}_{3} \mathrm{P}$ & $\mathrm{Ni}$ & $\mathrm{Ni}_{3} \mathrm{P}$ & $\mathrm{Ni}_{3} \mathrm{P}$ & $\mathrm{Ni}_{3} \mathrm{P}$ & $\mathrm{Ni}_{3} \mathrm{P}$ & $\mathrm{Ni}_{3} \mathrm{P}$ & $\mathrm{Ni}_{3} \mathrm{P}$ & $\mathrm{Ni}_{3} \mathrm{P}$ & $\mathrm{Ni}_{3} \mathrm{P}$ & $\mathrm{Ni}_{3} \mathrm{P}$ & $\mathrm{Ni}_{3} \mathrm{P}$ & $\mathrm{Ni}_{3} \mathrm{P}$ & $\mathrm{Ni}$ \\
\hline hkl & 031 & 231 & 330 & 112 & 111 & 240 & 141 & 222 & 341 & 440 & 332 & 620 & 233 & 460 & 172 & 462 & 222 \\
\hline
\end{tabular}


Table 4 Mechanical properties of Ni-P/SiC coatings at different annealing temperatures

\begin{tabular}{ccccc}
\hline Coatings & $\boldsymbol{H}(\mathbf{G P a})$ & $\boldsymbol{E}_{\mathbf{r}}(\mathbf{G P a})$ & $\boldsymbol{H} / \boldsymbol{E}_{\mathbf{r}}$ & $\boldsymbol{H}^{\mathbf{3}} / \boldsymbol{E}_{\mathbf{r}}^{2}(\mathbf{G P a})$ \\
\hline Ni-P/SiC-50 & $6.3 \pm 0.3$ & $158 \pm 8$ & 0.040 & 0.010 \\
Ni-P/SiC-350 & $8.2 \pm 0.5$ & $192 \pm 7$ & 0.043 & 0.015 \\
Ni-P/SiC-400 & $8.2 \pm 0.3$ & $156 \pm 5$ & 0.053 & 0.023 \\
Ni-P/SiC-450 & $7.8 \pm 0.3$ & $191 \pm 8$ & 0.041 & 0.013 \\
Ni-P/SiC-500 & $7.1 \pm 0.6$ & $214 \pm 9$ & 0.033 & 0.008 \\
\hline
\end{tabular}

